\title{
ENTREVISTA COM PROFESSORAS DO ENSINO FUNDAMENTAL I SOBRE EDUCAÇÃO PARA A SUSTENTABILIDADE ${ }^{53}$
}

\author{
Arthur William Pereira da Silva* \\ Ana Lúcia de Araújo Lima Coelho** \\ Helaine Cristine Carneiro dos Santos *** \\ Brenda Nathalia Fernandes Oliveira ****
}

Esta entrevista, realizada com as professoras do $2^{\circ}, 3^{\circ}$ e $5^{\circ}$ anos do ensino fundamental I de uma escola particular situada na cidade de João Pessoa - PB, objetiva analisar as concepções de sustentabilidade dessas professoras do ensino fundamental I, ou seja, como essas profissionais entendem a sustentabilidade e como se dá a educação para a sustentabilidade nessa escola e ainda como ela pode ser aperfeiçoada.

Acredita-se que a profundidade das concepções de sustentabilidade das professoras do ensino fundamental I possa influenciar diretamente em como as crianças irão conceber este fenômeno, tendo em vista que dentro do ambiente de educação para a sustentabilidade, desenvolvido na escola, as professoras são protagonistas nesse processo, sendo os indivíduos que mais interagem com as crianças a fim de contribuir para a expansão da sua visão sobre a temática, daí a relevância da presente entrevista.

Entrevistador: Professora do $5^{\circ}$ ano, você poderia me falar um pouco sobre as atividades que você participou aqui na escola durante o ano sobre sustentabilidade, escolher algumas que você lembre, e me dizer brevemente quais foram e como foram essas atividades?

Professora do $5^{\circ}$ ano: Uma atividade que a gente fez nesse ponto da sustentabilidade, que está bem fresquinha, é a mostra pedagógica, que nós trabalhamos efetivamente as 17 metas.

\footnotetext{
${ }^{53}$ A transcrição das respostas se deu sem qualquer correção ortográfica e gramatical com vistas a preservar a espontaneidade e o coloquialismo das mesmas.

* Doutorando em Administração pela Universidade Potiguar (UNP); Mestre em Administração pela Universidade Federal da Paraíba (UFPB); Mestre em Ambiente, Tecnologia e Sociedade pela Universidade Federal Rural do Semiárido (UFERSA); Especialista em Gestão Empresarial pela Universidade Potiguar (UNP); Graduado em Administração de Empresas pela Universidade Potiguar (UNP).

** Doutora em Administração e Turismo - UNIVALI; Mestrado em Administração - UFSC; Graduação em Ciências Contábeis - UFSC; Professora da Universidade Federal da Paraíba - UFPB.

*** Mestra em Administração - UFPB; Graduada em Administração - UFRPE; Professora da Universidade Federal da Paraíba - UFPB.

**** Especialista em saúde coletiva - UNOPAR e graduada em Nutrição - UNP; Professora da Universidade do Norte do Paraná - UNOPAR.
} 
Com a turma do $5^{\circ}$ eu trabalhei a meta 3 (Saúde e Qualidade), e foi um momento de reflexão, bastante intenso com a turma, onde a gente trabalhou essa questão da qualidade de vida num mundo mais sustentável, né?! Desenvolver saúde não só vem de questões de ter uma alimentação saudável, mas no todo. Quando você está bem emocionalmente, psicologicamente, socialmente... Então assim, a sustentabilidade permeou por todos esses caminhos, nessa atividade que foi muito significativa e muito importante pra turma.

Entrevistador: E a professora do $2^{\circ}$ ano, tem alguma coisa pra colocar?

Professora do $2^{\circ}$ ano: É, a questão da mostra pedagógica que a gente teve semana passada. No caso a minha, a gente trabalhou a meta 4 , diante das 17 metas globais colocadas pela ONU pra serem cumpridas até 2030, e a minha foi Educação de Qualidade (Meta 4), então a questão da sustentabilidade na educação, o cuidado com o outro na educação. Eu também lembro do projeto junino, né, o projeto São João, que a gente trabalhou a cultura nordestina, só que era nesse cuidado de sustentar a nossa cultura, a nossa cultura de raiz, o nosso início lá do nordeste, esse cuidado de sustentar também a cultura. Lógico, trazendo pro planeta, trazendo discussões de melhorar o planeta, mas trazendo pra nossa cultura, a festa de São João, que era de sustentar, da gente segurar de verdade essa nossa cultura, que é tão rica. A gente trabalha bastante isso também no projeto de São João. E também todos os nossos 'BOA TARDE' foram voltados, a maioria dos nossos, não vou generalizar também, mas a maioria, sempre a gente estava remetendo à sustentabilidade, sustentar o outro.

Professora do $5^{\circ}$ ano: Muito forte no início do ano, quando a gente traz o tema gerador: Nosso Planeta, Nossa casa! E aí é que os estudantes trazem, né, como esse planeta que é a nossa casa, será que é só o planeta em si, ou o planeta que começa em mim né, a casa que é o meu corpo, né, que passa por tudo isso pra chegar na casa maior, que é o nosso planeta. Isso foi muito forte também no início do ano quando a gente trabalhou o projeto do tema gerador.

Professora do $3^{\circ}$ ano: Como as meninas já citaram a mostra está muito fresca na nossa mente, né?! As meninas, cada uma trabalhou a sustentabilidade em um objetivo diferente, e eu na minha turma trabalhei a divulgação, a apresentação das 17 metas. Mas, uma fala que eu fiz hoje no Boa Tarde, e que eu achei muito coerente é que: trabalhar as 17 metas pra gente aqui no IPEI, trabalhar a sustentabilidade, independente da ONU ter lançado essa proposta agora, já é uma coisa que a gente, respira aqui, é uma coisa que permeia nosso dia a dia. Tudo que a gente 
faz, se planeja pra o Boa tarde a gente, planeja pensando na sustentabilidade. Se a gente planeja o São João, como citou a professora do $2^{\circ}$ ano, a gente planeja pensando na sustentabilidade. Então, assim, citar uma atividade que a gente faça com sustentabilidade, é dizer: trabalhar sustentabilidade aqui no IPEI, eu comecei no dia 02/02/2016, quando eu comecei as aulas, e vou encerrar no dia 19/12/2016 que é quando acaba o último dia de aula aqui com os meninos.

Entrevistador: Então seria uma coisa geral, né?

Professora do $3^{\circ}$ ano: É. Já é uma coisa que a gente... permeia tudo naturalmente.

Entrevistador: Você já participou ou teve alguma experiência a esse respeito (sobre sustentabilidade), fora da escola? Tipo: Trabalhos interiores, na família, igreja, algum grupo social que você faça parte? Alguma ação, alguma atividade que tenha a ver com esse tema? Não precisa ser de agora, pode ser bem anteriormente também.

Professora do $3^{\circ}$ ano: Não recordo não. Pode ser na minha casa?

Entrevistador: Pode.

Professora do $3^{\circ}$ ano: Na minha casa eu venho numa batalha com a questão da economia da água, pensando nessa questão do planeta mesmo. Minha mãe é viciada em limpeza, e aí é uma coisa complicada, tipo: Não precisa lavar a calçada todos os dias! Quando lavar use o balde. Então, assim, é o tempo todo, e é um exercício, é uma batalha que ainda não consegui vencer não na minha casa, mas é uma coisa que eu estou tentando conscientizar e já tá virando uma coisa "chata", porque já internalizou, aí minha irmã já pegou o discurso quando eu não estou em casa, mas eu acho que daqui a pouco eu consigo chegar lá.

Professora do $2^{\circ}$ ano: Eu me recordei agora... 2007 eu acho. Eu fazia o curso na ESPEP (Escola de Serviço Público do Estado da Paraíba), na época tinham muitos cursos pra Sapé-PB, e quem tinha acesso lá conseguia fazer os cursos gratuitos. Eu tinha um professor que era de Geografia, o nome dele era Jackson, não me lembro o sobrenome dele, ele é da UEPB, e um dos cursos que ele ofereceu pra gente, uma semana de aula, foi justamente sobre essa questão da sustentabilidade. Agora assim, eu não lembro o tema geral. Ele pegou dois dias na semana e trabalhou isso muito forte com a gente. Na época eu tinha 16-17 anos, e assim, ele tocou a gente 
de uma forma muito linda, desde as plantas que tinha lá no espaço que a gente fazia, que é lá na escola em Sapé, desde as plantas, até a questão de reutilizar os copos descartáveis, que a gente ficou a semana todinha utilizando o mesmo copo. Fez um mural de copos, e aquele copo era da professora do $2^{\circ}$ ano, então de segunda até sexta aquele copo era da professora do $2^{\circ}$ ano. Ninguém precisou pegar outro copo, e aí a partir desse momento, tinha todo aquele discurso em casa: cuidado com a água, cuidado com a luz. Que a consciência dos meus pais acredito que não era nem a questão do planeta, do sustentar, era a questão do gastar, da conta, né, do dinheiro. Mas todo aquele discurso que tinha em casa nos meus 16-17 anos, quando eu participei desse curso com o professor Jackson, eu entendia um dos motivos principais, o motivo principal, na verdade, que era de sustentar o planeta. Mas a gente vai passando o tempo, e vai vivenciando em vários lugares que não levam a sério isso, e nem internalizam isso. Fazem parte de campanhas, de uma coisa ou outra, mas internalizar, vivenciar diariamente, rotineiramente só aqui no IPEI, na verdade. Assim, é uma coisa que não é algo forçado, não é algo pensado que hoje tem que ser assim, amanhã tem que ser assim... Não! É uma coisa que a gente vai vivendo naturalmente, dia após dia. Então eu lembro disso. Eu lembro desse curso, e depois disso, esses anos todinhos, 2006-2007 [até hoje], 10 anos né, só aqui no IPEI vivenciando diariamente. Lógico, minhas atitudes sempre foram pensando no desperdício de tudo, mas mais nessa questão também do dinheiro, de não gastar. A visão do planeta, do cuidado com ele, eu passei a ter realmente quando eu cheguei aqui no IPEI.

Entrevistador: Mas essa visão de não gastar você acha que também tem a ver com sustentabilidade? De não gastar o dinheiro. Ou não?

Professora do $2^{\circ}$ ano: Tinha. Hoje no sentido que eu vejo que eu tinha é diferente. Na época, o não gastar pra mim o meu dinheiro, o que eu queria saber de não gastar não era o planeta, eu não gastava porque o meu dinheiro não precisava estar pagando tantos reais de conta de luz, se eu podia economizar pra tantos reais. E essa consciência, embora eu soubesse que a energia que a gente recebe a maioria vem de hidrelétrica, e passa pelo processo de seca, essas coisas, isso era a última coisa que eu pensava, porque eu pensava primeiro era no meu dinheiro na conta de luz ou meu dinheiro na conta de água. Meu pensamento de sustentabilidade, do cuidado realmente com o planeta, o natural, o que a gente vivencia, o que eu consegui internalizar, foi quando eu entrei aqui no IPEI. Antes era um cuidado, mas não era por causa do planeta não, era por conta do bolso realmente. Embora eu tenha tido esse curso que foi tão bom pra mim. Mas se não vivenciar vai esquecendo. 
Entrevistador: E você, Professora do $5^{\circ}$ ano?

Professora do $5^{\circ}$ ano: Ela falando [professora do $2^{\circ}$ ano], eu lembrei de uma vivência que eu passei ainda na época da faculdade. Que a gente fez um estágio numa escola, na usina Monte Alegre. E aí uma das coisas que, eu acho que até meio sem perceber, eles trabalhavam a questão da sustentabilidade, e tudo que era consumido na merenda da escola vinha de uma horta que eles tinham dentro da própria escola. Tinha um terreno grande, lateral e fundo, a escola não era tão grande assim, e aí temperos, verduras, legumes, algumas frutas vinham dessa horta pra produção da merenda na escola. Então a gente comentando, vivenciando isso a gente percebe que mesmo inconscientemente, aquelas pessoas, de alguma forma, estavam vivendo a sustentabilidade, ao estar consumindo produtos livres de agrotóxicos, que não poluem o planeta, tendo esse cuidado, que foi uma experiência. Mas aí como a professora do $2^{\circ}$ ano falou, essa questão mesmo desse cuidado, de se preocupar... hoje eu tenho até aquela preocupação de quando eu vou fazer a feira lá de casa, procurar feiras com produtos orgânicos, que antes eu nem me importava com isso. Então eu já o cuidado de procurar produtos orgânicos que são mais saudáveis, que não poluem o planeta, de quando estou dentro de casa apago as luzes, que não há necessidade de tantas luzes acesas, quando você vai lavar uma louça de ter o cuidado pra não gastar água, de não usar a máquina de lavar várias vezes durante a semana. Então tudo isso eu, como pessoa, comecei quando vim pra cá, ter essa vivência. Eu até comentava com Professora do $3^{\circ}$ ano de tantas coisas que a gente vai construindo dentro da gente depois que veio pra cá, pro IPEI. E, assim, já se torna meio que estranho diante de outras realidades na sociedade, e de outras realidades de outras escolas. Eu dou aulas de reforço, e conversando com algumas mães agora esse final de ano elas começaram a me questionar: tu conheces tal escola? O quê que tu achas? Aí eu disse: Mulher, é o seguinte, eu vou evitar de opinar por tal escola porque depois de tudo que a gente construiu, que eu construí de visão de mundo no IPEI, eu me sinto meio estranha em falar de outras escolas, porque, assim, é uma visão diferenciada, por mais que exista esse cuidado [com a sustentabilidade], você sente que é um cuidado superficial. Não é algo que é construído no dia a dia, e passa os muros da escola. Você percebe que as famílias também levam esse cuidado pra casa, e tem esse cuidado dos estudantes continuarem com isso no meio que eles vivem. E a gente também como professor, como educador.

Entrevistador: De que formas você trabalha a temática sustentabilidade com os seus alunos aqui na escola? Quais atividades e ações são desenvolvidas? 
Professora do $5^{\circ}$ ano: Quando a gente leva eles a refletirem sobre essa necessidade do cuidado, cuidado com o outro, de respeitar as diferenças que existem no outro, de respeitar a opinião de cada um, de perceber essa diferença que existe de opiniões. A gente tem falado muito agora dessa questão das mudanças, porque os meus estudantes estão no quinto ano, e vão passando por essas mudanças na puberdade, na adolescência, e a gente fala muito dessa questão do respeito, nesse processo de transformação no meu corpo, e no outro. E aí a sustentabilidade também passa por essas ações, de eu perceber, que eu estou crescendo e que eu preciso me respeitar, que eu preciso respeitar o outro, e levar isso pro meio que eu vivo, pra sociedade.

Entrevistador: Em que espaço isso acontece?

Professora do $5^{\circ}$ ano: Na sala de aula.

Entrevistador: Na sala de aula, durante as matérias convencionais então, né?!

Professora do $2^{\circ}$ ano: Também na sala de aula. Dentro de cada planejamento semanal que a gente vai construindo, dentro de cada disciplina, a gente vai vendo onde que vai entrar a sustentabilidade, e aí a gente vai bolando, junto com as coordenadoras, aulas que sempre venha essa consciência de sustentar e de respeito. Desde uma fila que organizada pra sair pra lanchar, até isso que a professora do $5^{\circ}$ ano disse, falou de respeitar as opiniões. É diário em cada disciplina, e em cada conteúdo como é que a gente vai trabalhar.

Professora do $3^{\circ}$ ano: Uma questão que eu acho importante a gente pontuar aqui é a questão do cuidado no Boa Tarde. Nós sempre fazemos atividades no Boa tarde, e elas são divididas em: um dia é reflexão, no outro é uma atividade de corpo, interpretação de algum texto ou de alguma música, pra gente não cantar ou cantar, cantar entendendo o que se canta, e porque canta. E aí quando é uma atividade de corpo, que envolve movimentos, nós costumamos dividir os alunos em grupos de quatro, fazendo grupos mistos $\left(2^{\circ}, 3^{\circ}, 4^{\circ}\right.$ e $5^{\circ}$ ano $)$ pra trabalhar neles esse cuidado mesmo, o respeito (eu sou maior, ele é menor, ele entendeu de uma forma e eu entendi de outra). A gente trabalha constantemente no Boa Tarde esses grupos mistos pra que eles consigam aceitar, consigam cuidar, consigam entender o limite do outro. 
Entrevistador: Através de que outras formas e atividades vocês acham que esse tema da sustentabilidade pode ser inserido aqui na escola?

Professora do $3^{\circ}$ ano: Nós vamos ficar conhecendo o tema gerador do ano que vem, na semana pedagógica. Eu sei que o tema do ano que vem vai ser um dos 17 objetivos, eu não sei exatamente qual é, mas planos futuros a gente só tem mesmo na primeira semana, porque mesmo trabalhando a sustentabilidade, tudo que a gente faz tem que permear pelo nosso tema gerador. Que esse ano nosso tema gerador foi: Nosso planeta, nossa casa, que a gente deu um enfoque. Aí a partir do nosso tema gerador do próximo ano é que a gente pode começar a preparar novas atividades, com novos desafios pra continuar esse tema da sustentabilidade durante os caminhos.

Entrevistador: Mas, mesmo que não viesse a ser colocado em prática na escola, mas você teria alguma ideia do que poderia ser feito, caso continuasse essa temática ano que vem pra trabalhar esse tema?

Professora do $3^{\circ}$ ano: [Ela conta que escreveram juntamente com os alunos, uma carta a 2 vereadores eleitos, que cobrava mais ações sustentáveis na cidade]. Cobrar as ações, junto aos vereadores, que escrevemos na carta.

Professora do $2^{\mathbf{0}}$ ano: Na minha visão como professora, já é tão abrangente, tão completo, tão bem pensado... Esse ano nós trabalhamos o bairro com os meninos do $5^{\circ}$ ao $9^{\circ} \ldots$ é tão abrangente, que se a gente pensar assim, a gente acha que não falta nada, eu na minha visão de professora. Até no poder público a escola já foi atrás, através dessa carta. Na minha visão hoje eu não acrescentaria nada, porque já é muito abrangente, desde os pequeninhos do ciclo I, até os meninos do $9^{\circ}$ que já tem uma visão mais de fazer, de executar.

Professora do $5^{\circ}$ ano: Eu acho que na verdade é dar prosseguimento a essas ideias que já foram pautadas. E, independente do tema gerador de 2017, eu acredito que a sustentabilidade permeia todos os espaços do IPEI porque está na essência da escola, da proposta pedagógica, do que se acredita, e do que você constrói quando vem pra cá. Então eu acho que é uma sequência que se guia em nossas aulas, independente da turma que esteja, essa construção do respeito, a diversidade, as diferenças, ao outro, a levar o outro a compreender isso no meio político, sem 
ser aquela política partidária, mas uma política que constrói, que se preocupa com o social, com o pessoal, com a comunidade. Acho que é uma sequência dessas atividades.

Entrevistador: Agora eu quero que você pense no que a gente conversou até agora, e me diga o que é sustentabilidade pra você e o que ela envolve.

Professora do $5^{\circ}$ ano: Sustentabilidade pra mim é uma construção de consciência de todo esse meio social, político, pessoal, onde eu construo esse respeito, esse cuidado a mim, ao outro e ao planeta que eu vivo, e aí envolve ações efetivas que partem desde essa construção de consciência no espaço escolar, até essa extensão pra família, pra o bairro onde essa família está inserida, pra o bairro onde essa escola está inserida, até chegar aos nossos representantes políticos, que vão poder também contribuir de forma efetiva, pra que essa sustentabilidade se espalhe num espaço maior, né, que vá além dos muros escolares, que seria a nossa cidade, o nosso estado, e consequentemente no Brasil, e no mundo todo.

Professora do $2^{\circ}$ ano: Sustentabilidade é uma construção de valores inicialmente dentro de você pra poder ser expandido para aqueles que cercam você. Esses valores não estão somente ligados à natureza em si do planeta Terra, mas dos valores como ser humano mesmo, como respeito, como ajuda, como compreensão, como companheirismo, como o fazer para o outro. Então é uma construção primeiramente interna, é algo que é internalizado em mim, pra poder ser exposto, pra poder ser colocado pros outros, porque se for algo que eu veja e copie, isso vai ser uma palestra, vai ser um tema, vai ser qualquer coisa, menos a internalização dessa sustentabilidade.

Professora do $3^{\circ}$ ano: É bem um resumo do que as meninas disseram mesmo. Quando eu penso nessa palavra sustentabilidade, ouvindo essa palavra há algum tempo atrás eu iria pensar pelo lado, não sei se diria prático, que era não cortar árvore, desligar a torneira quando estiver escovando os dentes, e aí depois que a gente vai vivenciando, sentindo, a gente vai internalizando, a gente vai percebendo que sustentabilidade é eu sustentar e conseguir suprir também a necessidade do outro. É eu me fortalecer, me sustentar, pra que eu consiga sustentar o outro. E não é sustentar o outro, só o outro, é a natureza, o olho d'água que tá nascendo e alguém foi lá e colocou um pedregulho e enterrou, é eu sustentar o outro enquanto pessoa, na sua forma mais integral. Sustentar o outro emocionalmente, sustentar o outro fisicamente, é eu poder estar bem, estar firme, estar sustentada pra eu poder estender minha mão pra dar ao outro, 
em qualquer que seja o aspecto. Seja ele social, emocional, espiritual, ambiental... é eu estar pronta pra ajudar o outro. 